\title{
Membrane Properties and Response to Opioids of Identified Dopamine Neurons in the Guinea Pig Hypothalamus
}

\author{
Michael D. Loose, Oline K. Ronnekleiv, and Martin J. Kelly \\ Department of Physiology, The Oregon Health Sciences University, Portland, Oregon 97201-3098
}

The electrophysiological properties and opioid responsiveness of the dopamine-containing neurons in the arcuate nucleus of the guinea pig hypothalamus were examined. Dopamine-containing neurons, identified immunocytochemically by the presence of tyrosine hydroxylase, had a mean lengthto-width profile of $14.9 \pm 4.4 \times 11.5 \pm 3.1 \mu \mathrm{m}(N=14)$. The $\mathrm{Na}^{+}$action potential of these neurons was of short duration, and induction of repetitive firing $(20-50 \mathrm{~Hz})$ caused an afterhyperpolarization of 6-9 $\mathrm{mV}$ in amplitude, with a decay half-time of approximately $1.5 \mathrm{sec}$. Dopamine-containing cells exhibited a low threshold spike, which induced 1-4 $\mathrm{Na}^{+}$action potentials. This potential had a threshold close to -65 $\mathrm{mV}$, could not be induced without prior hyperpolarization and was not sensitive to TTX. Dopamine-containing neurons also exhibited a time- and voltage-dependent inward current at potentials negative to $-70 \mathrm{mV}$, and $\mathrm{Cs}^{+}$blocked this conductance. The $\mu$-opioid agonist Tyr-D-Ala-Gly-mePhe-Gly-ol hyperpolarized (14 $3 \mathrm{mV}$ ) dopamine neurons via induction of an outward current ( $93 \pm 44 \mathrm{pA}$ near the resting membrane potential), which had a reversal potential similar to that expected for a selective potassium conductance. TTX (1 $\mu \mathrm{M})$ did not block the opioid effects. These results show that dopamine neurons of the arcuate nucleus differ in their intrinsic conductances and their responsiveness to opioids from other CNS dopaminergic neurons. Furthermore, opioid activation of a potassium conductance resulted in a direct hyperpolarization of dopamine neurons of the arcuate nucleus, and we suggest that this mechanism may underlie the effects of opioids on dopamine-mediated prolactin release.

Overwhelming evidence indicates that dopamine (DA) is the hypothalamic prolactin-inhibiting factor that tonically suppresses the release of prolactin from pituitary lactotrophs (see MacLeod, 1976; Cramer et al. 1979; McCann et al., 1984). Therefore, neurons of the A12 dopaminergic cell group (Hökfelt et al., 1984) in the arcuate nucleus (ARC) act as neurosecretory cells by releasing DA directly into the pituitary portal blood system (Ben-Jonathan et al., 1977), which carries the amine directly to the anterior pituitary gland. Furthermore, changes

\footnotetext{
Received Apr. 2, 1990; revised June 19, 1990; accepted June 28, 1990.

We appreciate the useful comments on the manuscript that were made by Drs. Alan North and John Williams. We also with to thank Martha Bosch and Barry Naylor for excellent technical assistance. This work was supported by U.S. Department of Health and Human Services Grant DA 05158. M.J.K. is the recipient of RCDA HD 00718.

Correspondence should be addressed to Michael D. Loose, Department of Physiology, The Oregon Health Sciences University, 3181 S.W. Sam Jackson Park Road, Portland, OR 97201-3098.

Copyright (C) 1990 Society for Neuroscience $0270-6474 / 90 / 113627-08 \$ 03.00 / 0$
}

in the output of DA may regulate the dynamic changes in prolactin secretion that occur during the preovulatory release of prolactin (Arbogast and Ben-Jonathan, 1988) and during lactation (Selmanoff and Wise, 1981).

Opioid compounds are potent stimulators of prolactin secretion (Meites, 1966; Ojeda et al., 1974; Rivier et al., 1977; Panerai et al., 1981; Wiesner et al., 1984), and opioids decrease the output of DA from A1 2 neurons (Grandison and Guidotti, 1977; Gudelsky and Porter, 1979; Haskins et al., 1981). Previously, we have shown that opioids inhibited the spontaneous activity of many of the neurons in the ARC, and that this inhibition was due to activation of $\mu$-receptors, which resulted in hyperpolarization of the cell membrane (Loose and Kelly, 1989, 1990). However, it has not been determined whether the dopaminergic neurons of the ARC are part of this responsive population. Therefore, in order to investigate the mechanism by which opioids inhibit DA neurons and increase prolactin release, we examined the response of identified DA neurons in the ARC to $\mu$-receptor activation. Furthermore, because DAcontaining cells of the ARC subserve a neurosecretory function, unlike other CNS dopaminergic neurons (Björklund and Lindvall, 1984), and because nothing is known about the electrophysiological characteristics of DA neurons in the hypothalamus, it was also of interest to examine the intrinsic membrane properties of the DA cells of the ARC.

\section{Material and Methods}

Preparation and maintenance of hypothalamic slices. Female guinea pigs (Topeka; $350-600 \mathrm{gm}$ ), born and raised in our colony, were ovariectomized 6-10 d prior to subcutaneous injection with estradiol benzoate $(25 \mu \mathrm{g})$ and were decapitated $24 \mathrm{hr}$ after the injection. The brain was removed, the hypothalamus was dissected, and coronal slices of 450 $\mu \mathrm{m}$ thickness were cut on a vibratome (Loose and Kelly, 1989). The slices were maintained in an auxiliary chamber at room temperature until transferred to an interface recording chamber (Kelly et al., 1984). In the recording chamber, the slice was maintained in an oxygenated $\left(95 \% \mathrm{O}_{2}, 5 \% \mathrm{CO}_{2}\right)$ environment at $35 \pm 1{ }^{\circ} \mathrm{C}$ and was perfused at 200 $500 \mu \mathrm{l} / \mathrm{min}$ with a modified Krebs-Ringer buffer $(\mathrm{NaCl}, 124 \mathrm{~mm} ; \mathrm{KCl}$, $5 \mathrm{~mm} ; \mathrm{NaH}_{2} \mathrm{PO}_{4}, 1.25 \mathrm{~mm} ; \mathrm{MgSO}_{4}, 2 \mathrm{~mm} ; \mathrm{CaCl}_{2}, 2 \mathrm{~mm} ; \mathrm{NaHCO}_{3}, 26$ mM; dextrose, $10 \mathrm{~mm}$; HEPES, $10 \mathrm{~mm}$ ).

Recording and data analyses. Intracellular recordings were made from ARC neurons using techniques similar to those previously described (Loose and Kelly, 1990). Microelectrodes were made from borosilicateglass micropipettes (1-mm outer diameter; A-M Systems) and were filled with a $2 \%$ biocytin solution in $1.75 \mathrm{M} \mathrm{KCl}$ and $0.025 \mathrm{M}$ Tris $(80-150$ $\mathrm{M} \Omega$ ). The biocytin solution was used in the electrode so that recorded neurons would contain biocytin and subsequently could be identified following reaction with a streptavidin-fluorophore conjugate (Horikawa and Armstrong, 1988). Intracellular potentials were amplified, and current was passed through the electrode using an Axoclamp 2A (Axon Instruments). Voltage-clamp recordings were made using a $1-3 \mathrm{kHz}$ switching frequency and $30 \%$ duty cycle in accordance with the procedures of Finkel and Redman (1985). Current and voltage traces were 
recorded on a chart recorder (Gould 2200) and periodically stored on an FM tape recorder (Vetter Instruments).

Electrophysiological analyses were performed only on cells that were recorded for at least $20 \mathrm{~min}$ and that exhibited overshooting action potentials and membrane potentials of $-50 \mathrm{mV}$ or more negative. Current-voltage relationships were obtained either by hyperpolarizing the neuron to potentials more negative than $-100 \mathrm{mV}$, then depolarizing at a rate of $1-2 \mathrm{mV} / \mathrm{sec}$ with the output fed directly to an X-Y plotter (Houston Instruments 200), or by passing a series of depolarizing and hyperpolarizing rectangular step commands of at least 150 -msec duration. The apparent input resistance of the cell membrane was calculated from the slope of the current-voltage plots in the region between

60 and $-80 \mathrm{mV}$. An approximation of the membrane time constant was obtained by measuring the amount of time required for a small current-induced voltage deflection to reach $63 \%$ of its final level. Numerical data are expressed as mean \pm SEM, except as noted. Comparisons between groups were evaluated using the $\chi^{2}$ statistic, and the level required for significance was set at $p<0.05$.

Pharmacological manipulations. Cells exhibited a stable membrane potential for $30-40 \mathrm{~min}$, during which time membrane properties were examined, before any pharmacological manipulations were performed. TTX $(1-2 \mu \mathrm{M})$, a sodium-channel blocker, and potassium-channel blockers [tetraethylammonium (TEA), $10 \mathrm{~mm}$; CsCl, 1-2 mM; 4-aminopyridine, $2 \mathrm{~mm}$ ] were added to the medium and applied by superfusion. Medium with a high concentration of $\mathrm{Mg}^{2+}(10 \mathrm{~mm})$ and a low $\mathrm{Ca}^{2+}$ concentration $(0.1 \mathrm{~mm})$ was also superfused. Tyr-D-Ala-Gly-mePheGly-ol (DAGOL, $20 \mu \mathrm{M}$ ), an opioid agonist selective for $\mu$-receptors (Handa et al., 1981; Williams and North, 1984), and naloxone (20 $\mu \mathrm{M})$, a relatively nonselective opioid-receptor antagonist, were applied by pressure ejection from micropipettes (diameter, 5-10 $\mu \mathrm{m}$ ) positioned just above the filter paper upon which the slice rested. There is a 20 to 40 -fold dilution of a drug applied with this "drop" technique by the time it reaches the cell membrane (Loose and Kelly, 1989).

Streptavidin-fluorescein isothiocyanate (FITC) staining. Following a recording, the slices were immersed in $4 \%$ paraformaldehyde in $0.03 \mathrm{M}$ Sorensen's phosphate buffer $(\mathrm{pH}, 7.4)$ for $90-100 \mathrm{~min}$. The slices were then soaked overnight in this buffer with $30 \%$ sucrose. The slices were frozen, $16-\mu \mathrm{m}$ sections were cut on a cryostat, and the sections were mounted on poly-L-lysine-coated slides. The slides from a given slice were washed with $0.1-\mathrm{M}$ sodium phosphate buffer $(\mathrm{pH}, 7.4)$, then streptavidin-FITC (1:600; Jackson Laboratories) was applied for $2 \mathrm{hr}$. The reaction was terminated by washing with buffer. The slides were scanned for the injected neuron with a Leitz fluorescence microscope (Dialux 20) using an $I_{2}$ filter, and the fluorescent cells were photographed.

Immunocytochemistry for tyrosine hydroxylase (TH). After localization of the biocytin-filled neurons, the slides containing the appropriate sections were processed for the presence of TH using fluorescence immunohistochemistry (Ronnekleiv et al., 1987). The antibody against $\mathrm{TH}$ is considered to label only DA-containing cells, as there are no noradrenergic or adrenergic neurons in the ARC (Moore and Bloom, 1979; Hökfelt et al., 1984). The section with the biocytin-identified neuron was washed and incubated overnight with an affinity-purified tyrosine hydroxylase antiserum (Pel-Freeze; $1: 750$ ) followed by a $2-\mathrm{hr}$ incubation with a donkey anti-rabbit $\gamma$-globulin conjugated to Texas Red (Jackson Laboratories; 1:50). The sections were washed with sodium phosphate buffer, and coverslips were applied using a glycerolglycine buffer $(2: 1 ; \mathrm{pH}, 8.6)$ containing $5 \% N$-propyl gallate. The immunostained cells were photographed through a Leitz $\mathbf{M}_{2}$ filter.

\section{Results}

\section{Double labeling and morphology of TH-containing neurons}

Neurons recorded in these experiments were located in the ARC as well as in the cell-poor zone immediately lateral to the ventrolateral ARC. The streptavidin-FITC reaction was performed on 130 neurons that were recorded for at least $10 \mathrm{~min} ; 114$ $(88 \%)$ of these cells were identified. Immunocytochemistry utilizing TH antiserum was performed on 56 of the biocytin-streptavidin-FITC labeled cells. The remaining cells were reacted with antisera to other antigens or were not further examined. Preliminary results had indicated that $\mathrm{TH}$-positive cells often exhibited a low threshold spike (I.TS; see next section). Thus, most neurons that had this characteristic were tested for $\mathrm{TH}$ immunoreactivity. Fourteen neurons were identified as immunopositive for TH. Often, the proximal dendrites as well as the somata were stained (Fig. 1). TH-identified neurons were located under the third ventricle in the rostral ARC $(N=1)$ and in the dorsomedial $(N=6)$ and ventrolateral $(N=7)$ aspects of the medial and caudal ARC. The size of the somata varied from small $(8 \times 11 \mu \mathrm{m})$ to large $(20 \times 20 \mu \mathrm{m})$ for this nucleus of the hypothalamus (Bodoky and Rethelyi, 1977; Van den Pol et al., 1984), with a mean length-by-width profile of $14.9 \pm 4.4 \times$ $11.5 \pm 3.1 \mu \mathrm{m}$ (mean $\pm \mathrm{SD}$ ). Two to 4 processes typically radiated from the cell body. Distal processes were traced for most TH-labeled cells for over $100 \mu \mathrm{m}$ (Fig. 1 $A$ ) in both the rostral-caudal direction and the dorsal-ventral direction. Long processes were observed less often traversing away from (i.e., lateral to) the third ventricle. In most instances, numerous varicosities were observed along the distal processes of the THcontaining neurons (Fig. $1 A$ ).

\section{Electrophysiological properties of $\mathrm{TH}$-containing neurons}

Neurons that werc $\mathrm{TH}$ positive and that met the critcria for electrophysiological analyses $(N=11)$ had a membrane potential of $-60 \pm 2 \mathrm{mV}$, an apparent input resistance of $348 \pm 44$ $\mathrm{M} \Omega$, and a membrane time constant of $20 \pm 3 \mathrm{msec}$. Nine $\mathrm{Hz}$ was the maximal spontaneous firing rate observed in TH-containing neurons, and most cells ( 8 of 11) were silent or fired at $2.5 \mathrm{~Hz}$ or less (mean firing rate, $2.5 \pm 0.9 \mathrm{~Hz}$ ). However, all TH-containing neurons could be induced to fire continuously at rates greater than $20 \mathrm{~Hz}$ (and up to $50 \mathrm{~Hz}$ ) during $400-\mathrm{msec}$ depolarizing current injections (Fig. $2 B$ ). Threshold for the onset of the fastest rising phase of the action potential was $-49 \pm 1$ $\mathrm{mV}(N=8)$ for TH-containing neurons, and the amplitude, measured from this point, was $67 \pm 3 \mathrm{mV}$. The duration of the action potential, measured at $1 / 3$ amplitude, was typically less than $1 \mathrm{msec}(0.8 \pm 0.1 \mathrm{msec}, N=7)$, and no "shoulder" was perceptible on the falling phase of the action potential (Fig. $2 \mathrm{~A}$ ). TH-containing ncurons also cxhibitcd a long-lasting aftcrhyperpolarization following a 400-msec depolarizing current pulse that induced repetitive action potentials (Fig. $2 B$ ). This afterhyperpolarization decayed to $1 / 2$ its magnitude in approximately $1.5 \mathrm{sec}$. The afterhyperpolarization that was induced by a current pulse that was $0.2 \mathrm{nA}$ above the threshold for induction of an action potential varied in amplitude from 6 to $9 \mathrm{mV}$ (7.5 $\pm 0.5 \mathrm{mV}, N=6$ ). The $\mathrm{TH}$-negative neurons that met our electrophysiological criteria $(N=28)$ had membrane properties that were not distinguishable from the TH-positive cells. They exhibited a membrane potential of $-59 \pm 1 \mathrm{mV}$, an input resistance of $334 \pm 34 \mathrm{M} \Omega$, a membrane time constant of 17 $\pm 1 \mathrm{msec}$, and a firing rate of $3.7 \pm 1.1 \mathrm{~Hz}$. The characteristics of the action potential in the $15 \mathrm{TH}$-negative cells that were examined (threshold $-51 \pm 2 \mathrm{mV}$; amplitude, $68 \pm 3 \mathrm{mV}$; duration, $0.8 \pm 0.1 \mathrm{msec}$ ) were essentially identical to those observed in the TH-positive neurons. The mean amplitude of the afterhyperpolarization in $17 \mathrm{TH}$-negative neurons was 6.7 $\pm 0.7 \mathrm{mV}$. In 4 additional TH-negative cells, no afterhyperpolarization could be induced.

A low-threshold and small-amplitude depolarizing potential that was induced only from hyperpolarized membrane potentials was observed in $8 \mathrm{TH}$-positive neurons. That is, a step depolarization to between -65 and $-60 \mathrm{mV}$ from a membrane potential of $-70 \mathrm{mV}$ or more negative caused a regenerative depolarizing potential that usually evoked 1-4 higher-threshold $\mathrm{Na}^{+}$action potentials (Fig. 2C). Perfusion with TTX (1-2 $\mu$ M) 

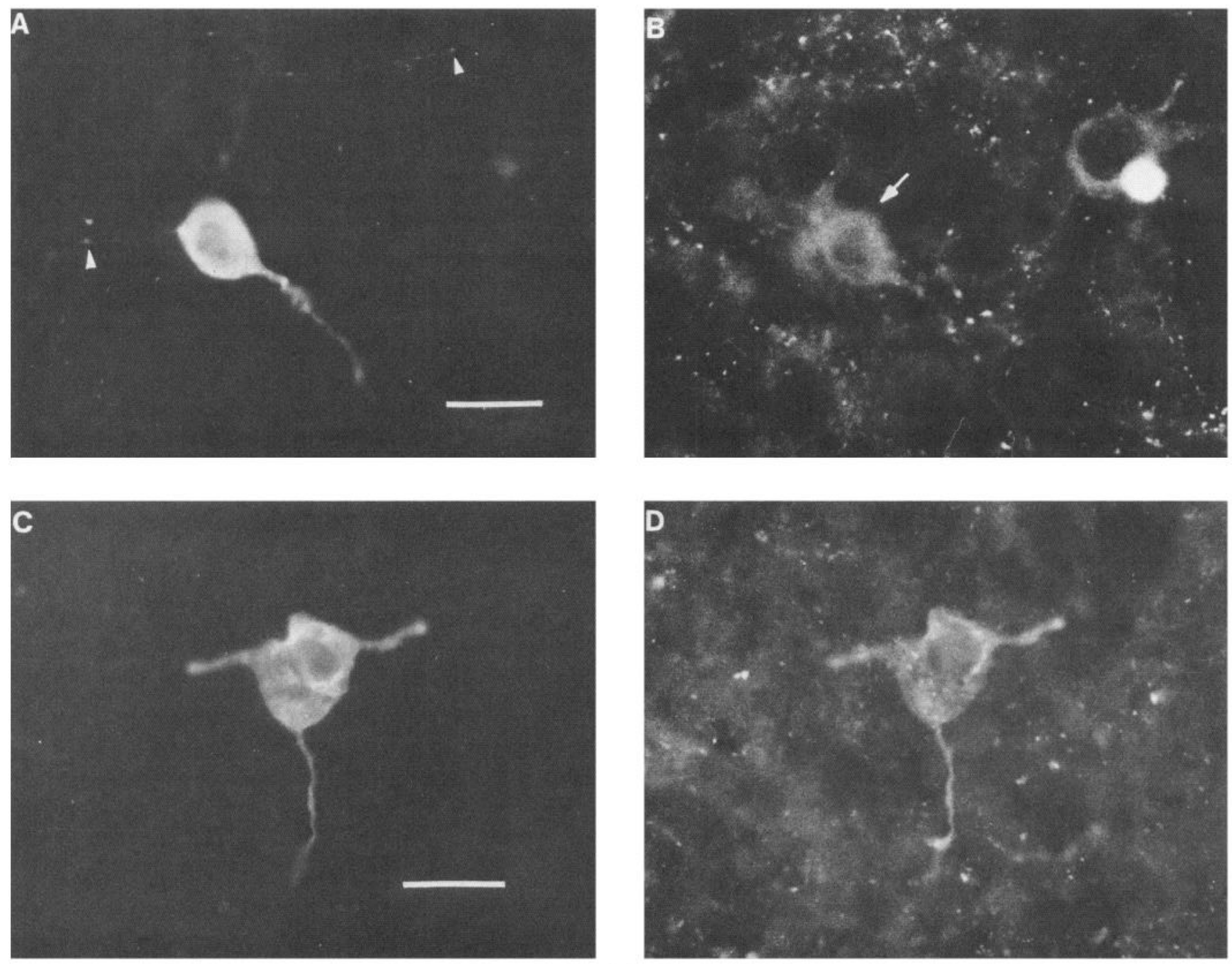

Figure 1. Double labeling of ARC DA neurons. A, Biocytin-streptavidin-FITC labeling of a neuron in the ventrolateral ARC. Varicosities were observed in distal fibers (arrowheads). B, TH immunostaining (Texas Red fluorescence) of the cell (arrow) in $A$. TH staining was evenly distributed throughout the cytoplasm and into the proximal fibers. Another TH-immunopositive neuron can be seen in the surrounding area. Scale bar, 20 $\mu \mathrm{m}$. $C$, Biocytin-streptavidin-FITC labeling of a neuron in the dorsomedial ARC. $D$, TH immunostaining of the cell in $C$. The presence of 3 or 4 immunopositive fibers was typical of TH neurons. Scale bar, $15 \mu \mathrm{m}$.

eliminated the fast $\mathrm{Na}^{+}$action potentials, but not the LTS $(N$ =6). In TTX, LTSs of 10-20 mV in amplitude and 40-100 msec in total duration were induced by depolarizing current pulses when the cell was held at $-90 \mathrm{mV}$ (Fig. $2 D$ ). When the membrane potential was held at -70 to $-80 \mathrm{mV}$, the LTS was of smaller amplitude but similar duration. Hyperpolarizing current pulses of $20-80 \mathrm{msec}$ duration were insufficient to deinactivate the conductance underlying the LTS, even when the membrane potential was driven from $-60 \mathrm{mV}$ to very negative potentials (e.g., $-110 \mathrm{mV}$ ). However, a hyperpolarizing pulse for $400 \mathrm{msec}$ to $-90 \mathrm{mV}$ allowed sufficient deinactivation to occur so that an LTS was induced at the end of the pulse. The LTS was eliminated by perfusion of the slice with medium containing $10 \mathrm{mM} \mathrm{Mg}^{2+}$ and $0.1 \mathrm{mM} \mathrm{Ca}^{2+}$ in $1 \mathrm{TH}$-positive cell, but was unaffected by $\mathrm{Cs}^{+}(1-2 \mathrm{~mm}$ ) or 4-aminopyridine ( $2 \mathrm{mM}$ ) in 3 other TH-containing cells. Thus, the LTS that occurred in TH-containing neurons in the ARC was similar to the LTS that was first described in thalamic neurons (Jahnsen and Llinás, 1984a,b), as it exhibited similar pharmacologic and voltage- dependent characteristics. TH-positive neurons were significantly more likely to exhibit an LTS than were other ARC neurons ( 16 of $75, p<0.01$ ). However, not all neurons in the ARC that had an LTS were identified as TH-positive, as 8 of the $25 \mathrm{TH}$-negative neurons that were evaluated also exhibited an LTS.

During a hyperpolarizing current pulse of 400 -msec duration, most of the TH-positive neurons ( 9 of 11) exhibited a timedependent rectifying conductance. This rectification appeared as a delayed depolarization of the voltage deflection. The "sag" observed under current-clamp conditions was found to be associated with a delayed-onset inward current under voltageclamp conditions. The inward current became apparent when the membrane potential was hyperpolarized beyond approximately $-70 \mathrm{mV}$ and became larger and reached maximal activation more quickly with greater hyperpolarization (Fig. 3). This time- and voltage-dependent conductance was also present in $81 \%$ of the TH-negative neurons examined $(N=27)$. Perfusion with $\mathrm{Cs}^{+}(1-2 \mathrm{~mm})$ eliminated both the sag and the un- 
A

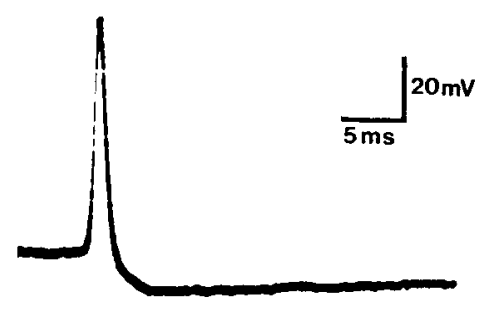

C

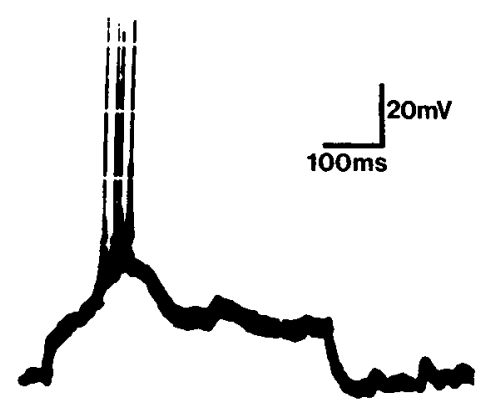

B

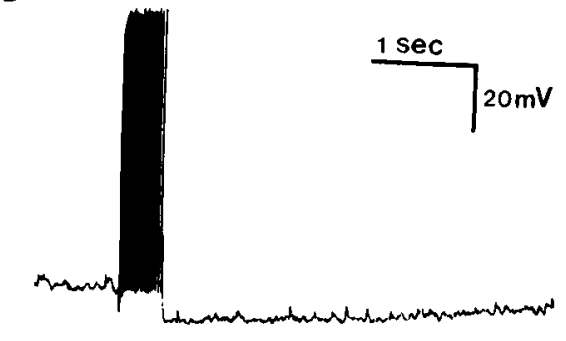

D

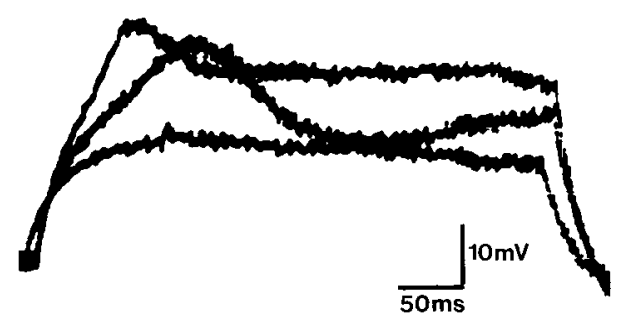

Figure 2. Intrinsic membrane properties of TH-identified neurons. $A$, An oscilloscope trace of a typical action potential during spontaneous firing. Start of the fast rising phase occurred at $-50 \mathrm{mV}$, and no shoulder was present on the descending phase of the spike. $B$, A $400-\mathrm{msec}$ depolarizing current pulse $(220 \mathrm{pA})$ induced rapid sustained firing. The cell exhibited an afterhyperpolarization of $9 \mathrm{mV}$ at the end of the pulse and slowly recovered to the resting membrane potential $(-66 \mathrm{mV})$. $C$. An oscilloscope trace showing an LTS that induced 4 action potentials. This cell was held at $-90 \mathrm{mV}$ with negative current $(110 \mathrm{pA})$, then a depolarizing pulse was administered. The LTS was approximately $20 \mathrm{mV}$ in amplitude and $100 \mathrm{msec}$ in duration. $D$. Three superimposed traces showing the membrane voltage deflections induced by depolarizing current pulses of 30 , 40 , and $50 \mathrm{pA}$. The $30-\mathrm{pA}$ current pulse did not elicit an LTS. The cell was held at $-85 \mathrm{mV}$ with $60 \mathrm{pA}$ to deinactivate the I.TS, which could not be induced from the resting membrane potential of $-62 \mathrm{mV}$. The LTS is observed in isolation due to the presence of $1 \mu \mathrm{M}$ TTX in the medium, which eliminated fast action potentials.

derlying current in TH-positive neurons ( $N=2$; Fig. 3). None of the other potassium- or sodium-channel antagonists that were tested, including TTX (1-2 $\mu \mathrm{M}, N=5)$, 4-aminopyridine ( $2 \mathrm{mM}$, $N=2)$, and TE $\Lambda(10 \mathrm{mM}, N-1)$, blocked the time-dependent rectification. In addition to the slower time-dependent rectifier, a rapidly activating, inwardly rectifying current occurred upon hyperpolarization of the membrane. This rectification is illustrated by the curvilinear appearance of the current-voltage plot depicting the membrane current measured immediately after settling of the capacitive transient $(<20 \mathrm{msec})$ and before significant activation of the time-dependent rectifier (Fig. $3 B$ ). This "instantaneous" inward rectifier also was blocked by $\mathrm{Cs}^{+}$(1-2 $\mathrm{mM}, N=2$ ), but was not examined in further detail. Both the instantaneous and the time-dependent rectification that we have observed at hyperpolarized membrane potentials in TH-positive cells are similar, physiologically and pharmacologically, to conductances that have been described previously in other CNS neurons (Halliwell and Adams, 1982; Constanti and Galvan, 1983; Crepel and Penit-Soria, 1986; Williams et al., 1988).

\section{Opioid effects on ARC neurons}

DAGOL, a selective $\mu$-opioid agonist, hyperpolarized the membrane and/or induced an outward current in voltage clamp in all TH-positive cells that were tested $(N=6$; Fig. $4 A)$. The DAGOL-induced hyperpolarization (14 $\pm 3 \mathrm{mV}, N=4)$ was accompanied in every case by a decrease in the apparent input resistance $(44 \pm 7 \%)$. The DAGOL-induced hyperpolarization was reversed by naloxone, an opioid-receptor antagonist. The outward current caused by DAGOL when TH neurons were held at $-60 \mathrm{mV}$ varied from 40 to $180 \mathrm{pA}(93 \pm 44 \mathrm{pA}, N=$
3). The intersection of current-voltage plots obtained before and after the opioid agonist was administered was $-94 \pm 2 \mathrm{mV}(N$ $=4$; Fig. $4 B$ ). The DAGOL-induced hyperpolarization of THcontaining neurons appeared to be a direct, postsynaptic action because TTX $(1 \mu \mathrm{M})$ did not block the effect $(N=2$; Fig. $4 C)$. Eight of $12 \mathrm{TH}$-negative neurons (67\%) also responded to DAGOL. The opioid-induced membrane hyperpolarization $(11 \pm$ $2 \mathrm{mV}, N=5)$ and decrease in input resistance $(45 \pm 12 \%, N=$ 5 ), as well as the opioid-induced outward current (100 $\pm 32 \mathrm{pA}$ at $-60 \mathrm{mV}, N=3$ ), were similar in magnitude to that observed in TH-positive neurons. In both the TH-positive and the THnegative neurons, the DAGOL-induced conductance increase was voltage sensitive such that the conductance increase was larger at more hyperpolarized membrane potentials (Fig. 4C). The conductance increase due to DAGOL was obtained by subtracting the total membrane current before DAGOL administration from that present after DAGOL application. The magnitude of the inward rectification of the DAGOL-induced current was quantified by comparing the conductance increase caused by DAGOL near -70 and near $-100 \mathrm{mV}(3.1 \pm 0.7 \mathrm{nS}$ vs. 6.4 $\pm 1.2 \mathrm{nS}, N=5$ ).

\section{Discussion}

Our results provide the first electrophysiological description of hypothalamic DA cells. DA neurons in the ARC spontaneously fired fast $\mathrm{Na}^{+}$action potentials at a relatively slow rate under resting conditions $(\sim 2.5 \mathrm{~Hz})$, but were able to sustain more rapid firing $(20-50 \mathrm{~Hz})$ when depolarized. The large input resistance and membrane time constant were consistent with the relatively small size and dendritic arborization of these par- 
vocellular hypothalamic neurons. The DA cells also exhibited a low-threshold $\mathrm{Ca}^{2+}$ spike upon depolarization from a membrane potential below $-65 \mathrm{mV}$. Furthermore, TH-identified neurons exhibited time-dependent rectification at membrane potentials negative to $-70 \mathrm{mV}$ and a long afterhyperpolarization following induction of repetitive firing. Finally, the DA cells in the ARC were hyperpolarized by an opioid agonist selective for $\mu$-receptors. These characteristics of identified DA neurons are similar, with 1 exception, to many of the TH-negative cells. The exception is that DA cells usually exhibited an LTS, whereas approximately 4 of 5 of the unidentified cells did not exhibit this potential. Unfortunately, because some cells with an LTS were found to be immunonegative to $\mathrm{TH}$, the presence of an LTS cannot be used as a sole and sufficient criterion to identify a cell as containing $\mathrm{TH}$. On the other hand, it is possible that the cells with an LTS that did not stain for TH were, in fact, dopaminergic, because double-labeling techniques are not $100 \%$ successful. Additional studies are necessary to determine what other cell types in the ARC, if any, express the LTS.

The response to a $\mu$-opioid agonist, DAGOL, by DA cells in the ARC was indistinguishable from that shown previously in unidentified neurons of the guinea pig ARC (Loose and Kelly, 1990 ) and from the response of identified $\beta$-endorphin neurons in the ARC (Kelly et al., 1990). The DAGOL-induced currents had similar magnitudes and reversal potentials. TTX did not block the response, and the opioid conductance had a similar voltage dependence. Therefore, the $\mu$-receptor-activated, potassium selective conductance that has been described in unidentified neurons of the ARC (Loose and Kelly, 1990) is most probably the same opioid-gated conductance present in identified DA cells in the ARC.

The most clearly delineated function of ARC DA neurons is as the prolactin-inhibiting factor (MacLeod, 1976; Ben-Jonathan et al., 1977; Gibbs and Neill, 1978; Cramer et al., 1979; McCann et al., 1984). Opioids are known to inhibit turnover of DA in the median eminence (Ferland et al., 1977; Van Loon et al., 1980), suppress DA levels in the portal blood (Gudelsky and Porter, 1979; Haskins et al., 1981), and elevate plasma prolactin levels (Ojeda et al., 1974; Rivier et al., 1977; Meites et al., 1979; Haskins et al., 1981). However, it had not been clear whether opioid inhibition of DA release from the DA neurons in the ARC is a direct or an indirect effect, possibly involving a circuit using serotonin (Koenig et al., 1979; Meites et al., 1979; Spampinato et al., 1979). Several reports have indicated that an anatomical substrate exists for a direct opioid action on ARC DA neurons. In rodents (Morel and Pelletier, 1986) and primates (Goldsmith et al., 1989), fibers containing $\beta$-endorphin, an endogenous opioid ligand capable of activating $\mu$-receptors on neurons (North et al., 1987), have been reported to contact somatic and dendritic membranes of DA neurons in the ARC. We found that all of the identified DA neurons that were tested were hyperpolarized by an opioid $\mu$-receptor agonist. These results suggest that release of $\beta$-endorphin would directly hyperpolarize ARC DA neurons and thus describe a physiological mechanism for the opioid regulation of prolactin release.

The electrophysiological characteristics of DA neurons in the ARC differ in several ways both from other hypothalamic neuroscerctory cclls and from other DA cclls. For decades, the magnocellular neurons of the supraoptic and paraventricular hypothalamic nuclei, which secrete vasopressin and oxytocin, have been considered the prototypical mammalian neurosecre-

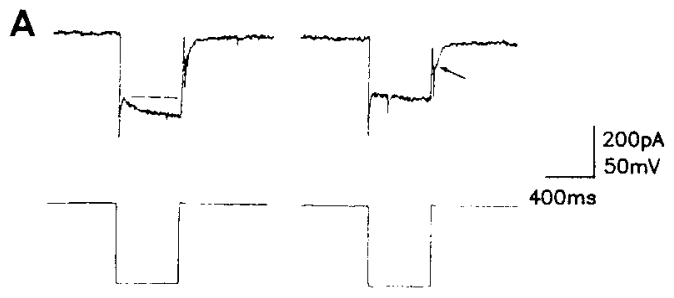

B

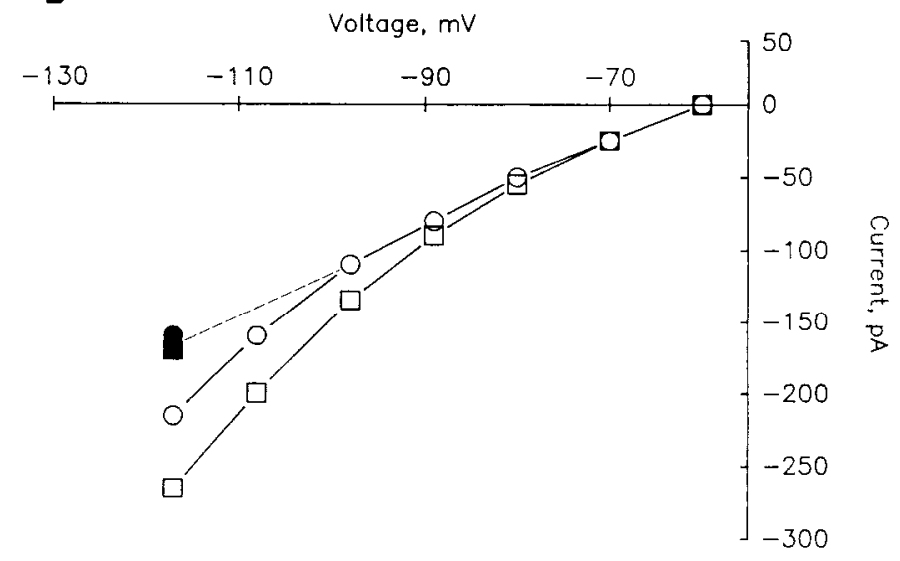

Figure 3. Two inwardly rectifying conductances are activated by hyperpolarization in TH-positive neurons. $A, \mathrm{CsCl}$ reduces the "instantaneous" membrane current response to hyperpolarizing voltage steps and eliminates a slowly developing inward current. Upper traces are examples of the current responses to a $-60 \mathrm{mV}$ step command (holding potential of $-60 \mathrm{mV}$ ) before and after perfusion with $\mathrm{CsCl}(2 \mathrm{~mm})$. The dashed line indicates the magnitude of the time-dependent inward current before $\mathrm{Cs}^{+}$. These recordings were made in the presence of TTX $(1 \mu \mathrm{M})$. Note that the $\mathrm{Cs}^{+}$does not block the apparent inward $\mathrm{Ca}^{2+}$ current (arrow) that underlies the LTS. $B$, The current-voltage relationships of TH-containing neurons indicated the presence of a timedependent as well as a time-independent rectification at membrane potentials negative to $-70 \mathrm{mV}$. Inward rectification was present at the beginning of hyperpolarizing pulses (measured at the end of the capacilive transient; open circles) and was larger in magnitude at the end of the pulses (open squares). Both the time-dependent and the "instantaneous" rectification were reduced when $\mathrm{CsCl}(2 \mathrm{~mm})$ was added to the perfusate. Solid symbols represent data collected in the presence of $\mathrm{Cs}^{+}$; at membrane potentials of $-100 \mathrm{mV}$ and more positive, the data points obtained in $\mathrm{Cs}^{+}$overlaid the open circles.

tory neurons (Scharrer and Scharrer, 1940; Poulain and Wakerley, 1982; Morris et al., 1987; Renaud, 1987). However, it has not been clear whether the electrophysiological characterization of these magnocellular neurons would be applicable to the many other neurosecretory neurons in the hypothalamus. DA neurons in the ARC were characterized by an LTS, whereas this conductance is absent in magnocellular hypothalamic neurons (Bourque et al., 1985, 1986). Furthermore, magnocellular neurons have broad action potentials ( $>1.5 \mathrm{msec}$ ), which have a shoulder on the repolarization phase that is due to a high-threshold calcium conductance (Mason and Leng, 1984; Bourque and Renaud, 1985), and ARC DA neurons have shorter-duration action potentials with no shoulder. The functional ramifications of these electrophysiological differences are unknown but might be expected to alter the nature of the neurohumoral signal produced by these neurons. In this context, it is interesting to note that neurosecretion by the magnocellular neurons is quite different from that of the DA neurons of the ARC. That is, large 
A
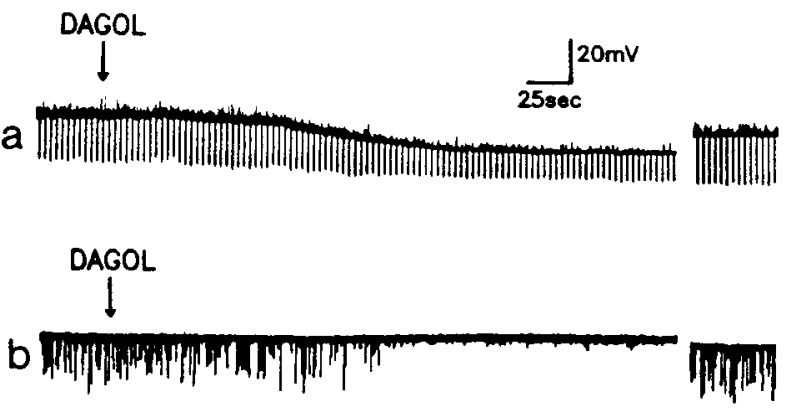

$\int_{10 \mathrm{soc}}^{2000 \mathrm{~A}}$

B
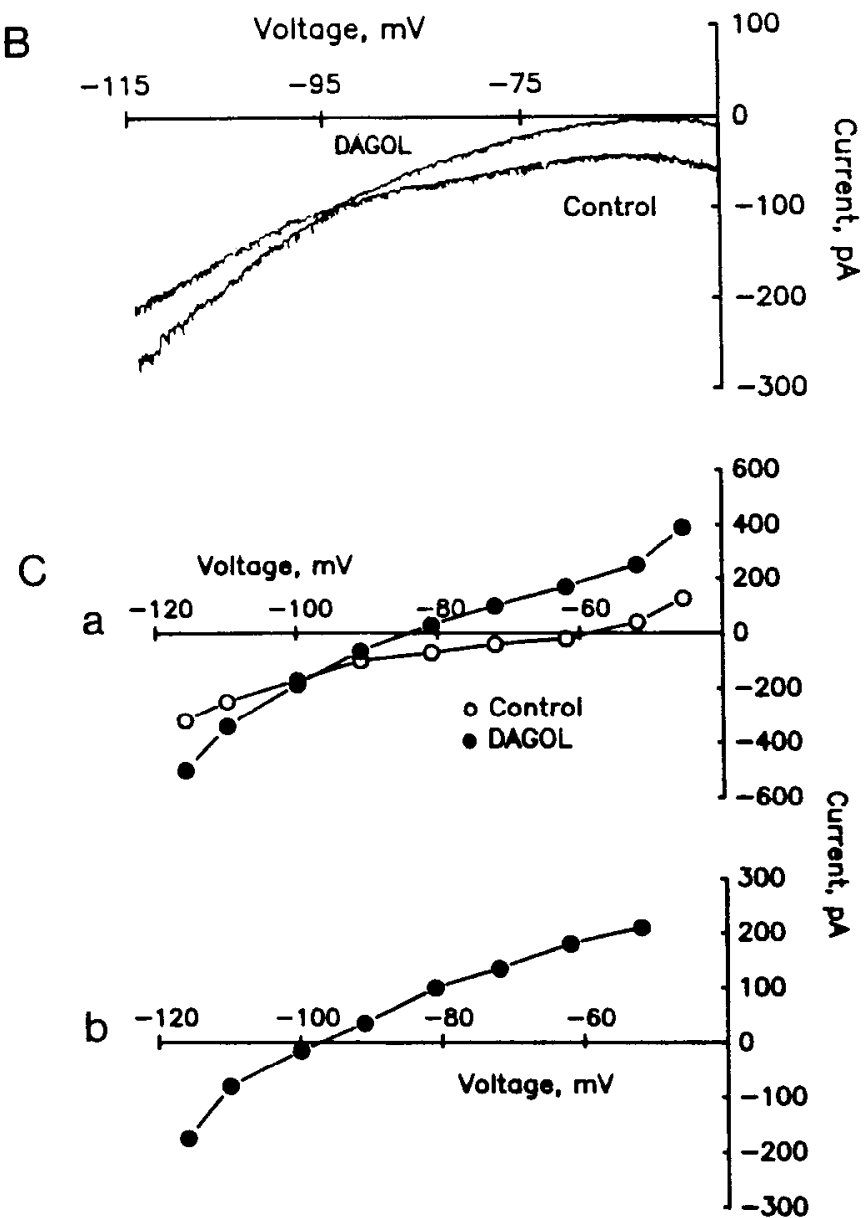

Figure 4. A $\mu$-opioid agonist, DAGOL, hyperpolarized TH cells and induced inward current near the resting membrane potential. The DAGOL-induced current became outward at potentials negative to the $\mathrm{K}^{+}$ reversal potential and exhibited inward rectification. $A$, Membrane responses to DAGOL in current clamp $(a)$ and voltage clamp $(b)$ of 2 TH-positive neurons. $a$, DAGOL caused a $14-\mathrm{mV}$ hyperpolarization that was associated with a decrease in the apparent input resistance. The downward deflections represent the membrane voltage response to constant-current hyperpolarizing pulses $(0.2 \mathrm{~Hz})$. After washout of DAGOL, the cell returned to its original membrane potential $(-65 \mathrm{mV})$ and input resistance $(380 \mathrm{M} \Omega)$; the break in the trace is $24 \mathrm{~min} . b$, DAGOL induced an outward current of $40 \mathrm{pA}$ at the holding potential of $-65 \mathrm{mV}$ in the cell shown in Figure 1,C and $D$. The downward deflections represent large, spontaneous postsynaptic currents that disappeared after DAGOL was applied. The break in the trace represents 24 minutes. $B$, Steady-state current-voltage plots of the voltage-clamped cell show that DAGOL increased the slope conductance of the currentvoltage relationship, and that the reversal potential of the DAGOL- boluses of oxytocin and vasopressin are released into the systemic circulation and act at distant sites within the body (Poulain and Wakerley, 1982), whereas much smaller quantities of DA need to be released into the portal blood system that directly links the site of release of DA in the median eminence with the pituitary lactotrophs (Ben-Jonathan et al., 1977; Gibbs and Neill, 1978).

There are several conductances, such as a low-threshold $\mathrm{Ca}^{2+}$ dependent conductance and a time-dependent rectifier, which are common to the DA neurons of the ARC (present observations) and the DA cells of the substantia nigra (Llinás et al., 1984; Kita et al., 1986; Grace and Onn, 1989; Lacey et al., 1989). Ilowever, the neurons of these dopaminergic cell groups differ in at least 3 features. DA cells in the substantia nigra, in contrast to DA cells in the ARC, have a broad action potential (>1.5 msec; Grace and Bunney, 1983; Matsuda et al., 1987; Grace and Onn, 1989; Lacey et al., 1989). The midbrain DA cells also exhibit strong accommodation such that they typically are unable to sustain firing rates greater than $10-15 \mathrm{~Hz}$ in vivo (Grace and Bunney, 1984) and in vitro (Lacey et al., 1989), whereas ARC DA neurons are able to sustain firing rates of up to $50 \mathrm{~Hz}$. Third, presumptive DA cells of the substantia nigra pars compacta are not hyperpolarized by $\mu$-receptor opioid activation (Lacey et al., 1989). These differences between the DAcontaining neurons in the substantia nigra and the hypothalamic ARC clearly suggest that the expression of a dopaminergic phenotype by a neuron in the brain does not necessarily correlate with a particular set of conductances being expressed by that neuron. On the other hand, the marked similarities among ARC neurons, irrespective of transmitter content and function, might lead one to speculate that the location or origin of hypothalamic neurons influences the electrophysiological conductances expressed by these cells.

The heterogeneity and small size of the neurons in the hypothalamus previously have hindered attempts to examine the electrophysiological characteristics of many of the neuroendocrine-releasing and -inhibiting factors, including DA. By combining intracellular recording of hypothalamic neurons with immunocytochemical staining for $\mathrm{TH}$, we have identified several membrane conductances intrinsic to DA neurons in the ARC that differ from those present in other dopaminergic neurons. Furthermore, these data lead us to suggest that a direct opioid inhibition of ARC DA neurons, mediated by $\mu$-receptor activation of a specific potassium conductance, is an integral component of the ncurocndocrinc circuits that incorporate ARC DA neurons.

\section{References}

Arbogast LA, Ben-Jonathan N (1988) The preovulatory prolactin surge: an evaluation of the role of dopamine. Endocrinology 123:2690-2695. Ben-Jonathan N, Oliver C, Weiner HJ, Mical RS, Porter JC (1977)

induced current in this ccll was $95 \mathrm{mV}$. Traces were obtained on-line during a slow $(\sim 1 \mathrm{mV} / \mathrm{sec})$ ramp depolarization from a $-115 \mathrm{mV}$ holding potential. The postsynaptic current fluctuations have been truncated. $C$, The conductance increase caused by DAGOL exhibited inward rectification. $a$, Current-voltage relationships of another TH cell in the presence and absence of DAGOL. $b$, Plot of the DAGOL-induced current (difference between control and response values in $a$ versus the membrane potential). Note the increase in slope conductance at the more negative potentials. TTX $(1 \mu \mathrm{M})$ was present in the medium during this experiment. 
Dopamine in hypophysial portal plasma of the rat during the estrous cycle and throughout pregnancy. Endocrinology 100:452-458.

Björklund A, Lindvall O (1984) Dopamine-containing systems in the CNS. In: Handbook of chemical neuroanatomy: classical transmitters in the CNS, Pt 1 (Björklund A, Hökfelt T, eds), pp 55-122. Amsterdam: Elsevier.

Bodoky M, Rethelyi M (1977) Dendritic arborization and axon trajectory of neurons in the hypothalamic arcuate nucleus of the rat. Exp Brain Res 28:543-555.

Bourque CW, Renaud LP (1985) Calcium-dependent action potentials in rat supraoptic neurosecretory neurones recorded in vitro. J Physiol (Lond) 363:419-428.

Bourque CW, Randle JCR, Renaud LP (1985) Calcium-dependent potassium conductance in rat supraoptic nucleus neurosecretory neurons. J Neurophysiol 54:1375-1382

Bourque CW, Brown DA, Renaud LP (1986) Barium ions induce prolonged plateau depolarizations in neurosecretory neurones of the adult rat supraoptic nucleus. J Physiol (Lond) 375:573-586.

Constanti A, Galvan M (1983) Fast inward-rectifying current accounts for anomalous rectification in olfactory cortex neurones. J Physiol (Lond) 385:153-178.

Cramer OM, Parker CR, Porter JC (1979) Secretion of dopamine into hypophysial portal blood by rats bearing prolactin-secreting tumors or ectopic pituitary glands. Endocrinology 105:636-640.

Crepel F, Penit-Soria J (1986) Inward rectification and low threshold calcium conductance in rat cerebellar purkinje cells. An in vitro study. J Physiol (Lond), 372:1-23.

Ferland L, Fuxe K, Eneroth P, Gustafsson J, Skett P (1977) Effects of methionine-enkephalin on prolactin release and catecholamine levels and turnover in the median eminence. Eur J Pharmacol 43:89-90.

Finkel AS, Redman SJ (1985) Optimal voltage clamping with single microelectrode. In: Voltage and patch clamping with microelectrodes (Smith TG Jr, Lecar H, Redman SJ, Gage PW, eds), pp 95-120. Bethesda, MD: Am Physiol Soc.

Gibbs DM, Neill JD (1978) Dopamine levels in hypophysial stalk blood in the rat are sufficient to inhibit prolactin secretion in vivo. Endocrinology 102:1895-1900.

Goldsmith PC, Boggan JE, Thind KK (1989) Opioid neurons synapse on tuberoinfundibular dopamine neurons in the arcuate nucleus of juvenile monkeys. Soc Neurosci Abstr 15:722.

Grace AA, Bunney BS (1983) Intracellular and extracellular electrophysiology of nigral dopaminergic neurons -1 . Identification and characterization. Neuroscience 10:301-315.

Grace AA, Bunney BS (1984) The control of firing patterns in nigral dopamine neurons: burst firing. J Neurosci 4:2877-2890.

Grace AA, Onn S-P (1989) Morphology and electrophysiological properties of immunocytochemically identified rat dopamine neurons recorded in vitro. J Neurosci 9:3463-3481.

Grandison L, Guidotti A (1977) Regulation of prolactin release by endogenous opiates. Nature 270:357-359.

Gudelsky GA, Porter JC (1979) Morphine- and opioid peptide-induced inhibition of the release of dopamine from tuberoinfundibular neurons. Life Sci 25:1697-1702.

Halliwell JV, Adams PR (1982) Voltage-clamp analysis of muscarinic excitation in hippocampal neurons. Brain Res 250:71-92.

Handa BK, Lane AC, Lord AH, Morgan BA, Rance MJ, Smith CFC (1981) Analogues $\beta$-LPH ${ }^{61-64}$ possessing selective agonist activity at $\mu$-opiate receptors. Eur J Pharmacol 70:531-540.

Haskins JT, Gudelsky GA, Moss RL, Porter JC (1981) Iontophoresis of morphine into the arcuate nucleus: effects on dopamine concentrations in hypophysial portal plasma and serum prolactin concentrations. Endocrinology 108:767-771.

I Iökfelt T, Johansson O, Goldstein M (1984) Central catecholamine neurons as revealed by immunohistochemistry with special reference to adrenaline neurons. In: Handbook of chemical neuroanatomy (Björklund A, Hökfelt T, eds), pp 157-276. Amsterdam: Elsevier.

Horikawa K, Armstrong WE (1988) A versatile means of intracellular labeling: injection of biocytin and its detection with avidin conjugates. J Neurosci Meth 25:1-11.

Jahnsen H, Llinás RR (1984a) Electrophysiological properties of guinea-pig thalamic neurones: an in vitro study. J Physiol (Lond) 349: 205-226.

Jahnsen H, Llinás RR (1984b) Ionic basis for the electroresponsiveness and oscillatory properties of guinea-pig thalamic neurones in vitro. $\mathrm{J}$ Physiol (Lond) 349:227-247.
Kelly MJ, Ronnekleiv OK, Eskay RL (1984) Identification of estrogenresponsive LHRH neurons in the guinea pig hypothalamus. Brain Res Bull 12:399-407.

Kelly MJ, Loose MD, Ronnekleiv OK (1990) Opioids hyperpolarize $\beta$-endorphin neurons via $\mu$-receptor activation of a potassium conductance. Neuroendocrinology 52:268-275.

Kita T, Kita II, Kitai ST (1986) Electrical membrane properties of rat substantia nigra compacta neurons in an in vitro slice preparation. Brain Res 372:21-30.

Koenig JI, Mayfield MA, McCann SM, Krulich L (1979) Stimulation of prolactin secretion by morphine: role of the central serotonergic system. Life Sci 25:853-864.

Lacey MG, Mercuri NB, North RA (1989) Two cell types in rat substantia nigra zona compacta distinguished by membrane properties and the actions of dopamine and opioids. I Neurosci 9:1233-1241.

Llinás R, Greenfield SA, Jahnsen H (1984) Electrophysiology of pars compacta cells in the in vitro substantia nigra - a possible mechanism for dendritic release. Brain Res 294:127-132.

Loose MD, Kelly MJ (1989) Opioid inhibition of spontaneously active neurons of the rat arcuate nucleus in vitro. Brain Res Bull 22:819 823.

Loose MD, Kelly MJ (1990) Opioids act at $\mu$-receptors to hyperpolarize arcuate neurons via an inwardly rectifying potassium conductance. Brain Res 513:15-23.

MacLeod RM (1976) Regulation of prolactin secretion. In: Frontiers in neuroendocrinology, Vol 4 (Martini L, Ganong WF, eds), pp 169194. New York: Raven.

Mason WT, Leng G (1984) Complex action potential waveform recorded from supraoptic and paraventricular neurones of the rat: evidence for sodium and calcium spike components at different membrane sites. Exp Brain Res 56:135-143.

Matsuda Y, Fujimura K, Yoshida S (1987) Two types of neurons in the substantia nigra pars compacta studied in a slice preparation. Neurosci Res 5:172-179.

McCann SM, Lumpkin MD, Mizunuma H, Khorram O, Ottlecz A, Samson WK (1984) Peptidergic and dopaminergic control of prolactin release. TINS 7:127-131.

Meites J (1966) Control of mammary growth and lactation. In: Frontiers in neuroendocrinology, Vol 1 (Martini L, Ganong WF, eds), pp 669-707. New York: Academic.

Meites J, Bruni JF, Van Vugt DA, Smith AF (1979) Relation of endogenous opioid peptides and morphine to neuroendocrine functions. Life Sci 24:1325-1336.

Moore RY, Bloom FE (1979) Central catecholamine neuron systems: anatomy and physiology of the norepinephrine and epinephrine systems. Annu Rev Neurosci 2:113-168.

Morel G, Pelletier G (1986) Endorphinic neurons are contacting the tuberoinfundibular dopaminergic neurons in the rat brain. Peptides 7:1197-1199.

Morris JF, Chapman DB, Sokol HW (1987) Anatomy and function of the classic vasopressin-secreting hypothalamus-neurohypophysial system. In: Vasopressin: principles and properties (Gash DM, Boer GJ, eds), pp 1-90. New York: Plenum.

North RA, Williams JT, Surprenant A, Christie MJ (1987) $\mu$ and $\delta$ receptors belong to a family of receptors that are coupled to potassium channels. Proc Natl Acad Sci USA 84:5487-5491.

Ojeda SR, Harms PG, McCann SM (1974) Possible role of cyclic AMP and prostaglandin $E_{1}$ in the dopaminergic control of prolactin release. Endocrinology 95:1694-1703.

Panerai AE, Casanueva F, Martini A, Mantegazza P, DiGiulio A (1981) Opiates act centrally on GH and PRL release. Endocrinology 108: 2400-2402.

Poulain DA, Wakerley JB (1982) Electrophysiology of hypothalamic magnocellular neurones secreting oxytocin and vasopressin. Neuroscience 7:773-808.

Renaud LP (1987) Magnocellular neuroendocrine neurons: update on intrinsic properties, synpatic inputs and neuropharmacology. TINS 10:498-502.

Rivier C, Vale W, Ling N, Brown M, Guillemin R (1977) Stimulation in vivo of the secretion of prolactin and growth hormone by $\beta$-endorphin. Endocrinology 100:238-241.

Ronnekleiv OK, Adelman JP, Weber E, Herbert E, Kelly MJ (1987) Immunohistochemical demonstration of proGnRH and $\mathrm{GnRH}$ in the preoptic-basal hypothalamus of the primate. Neuroendocrinology 45: 518-521. 
Scharrer E, Scharrer B (1940) Secretory cells within the hypothalamus. Res Publ Assoc Res Nerv Ment Dis 20:170-194.

Selmanoff M, Wise PM (1981) Decreased dopamine turnover in the median eminence in response to suckling in the lactating rat. Brain Res 212:101-115.

Spampinato S, Locatelli V, Cocchi D, Vicentini L, Bajusz S, Ferri S, Müller EE (1979) Involvement of brain serotonin in the prolactinreleasing effect of opioid peptides. Endocrinology 105:163-170.

Van den Pol AN, Herbst RS, Powell JF (1984) Tyrosine hydroxylaseimmunoreactive neurons of the hypothalamus: a light and electron microscopic study. Neuroscience 13:1117-1156.
Van Loon GR, Ho D, Kim C (1980) $\beta$-endorphin-induced decrease in hypothalamic dopamine turnover. Endocrinology 6:76-80.

Wiesner JB, Koenig JI, Krulich L, Moss RL (1984) Site of action for $\beta$-endorphin-induced changes in plasma luteinizing hormone and prolactin in the ovariectomized rat. Life Sci 34:1463-1473.

Williams JT, North RA (1984) Opiate-receptor interactions on single locus coeruleus neurones. Mol Pharmacol 26:489-497.

Williams JT, Colmers WF, Pan ZZ (1988) Voltage- and ligand-activated inwardly rectifying currents in dorsal raphe neurons in vitro. $J$ Neurosci 8:3499-3506. 